\title{
Low-speed Aerodynamic Investigations of a Hybrid Wing Body Configuration
}

\author{
Dan D. Vicroy ${ }^{1}$, Gregory M. Gatlin ${ }^{2}$, Luther N. Jenkins ${ }^{3}$, Patrick C. Murphy ${ }^{4}$ and Melissa B. Carter ${ }^{5}$ \\ NASA Langley Research Center, Hampton, VA, 23681, USA
}

\begin{abstract}
Two low-speed static wind tunnel tests and a water tunnel static and dynamic forcedmotion test have been conducted on a hybrid wing-body (HWB) twinjet configuration. These tests, in addition to computational fluid dynamics (CFD) analysis, have provided a comprehensive dataset of the low-speed aerodynamic characteristics of this nonproprietary configuration. In addition to force and moment measurements, the tests included surface pressures, flow visualization, and off-body particle image velocimetry measurements. This paper will summarize the results of these tests and highlight the data that is available for code comparison or additional analysis.
\end{abstract}

\section{Nomenclature}

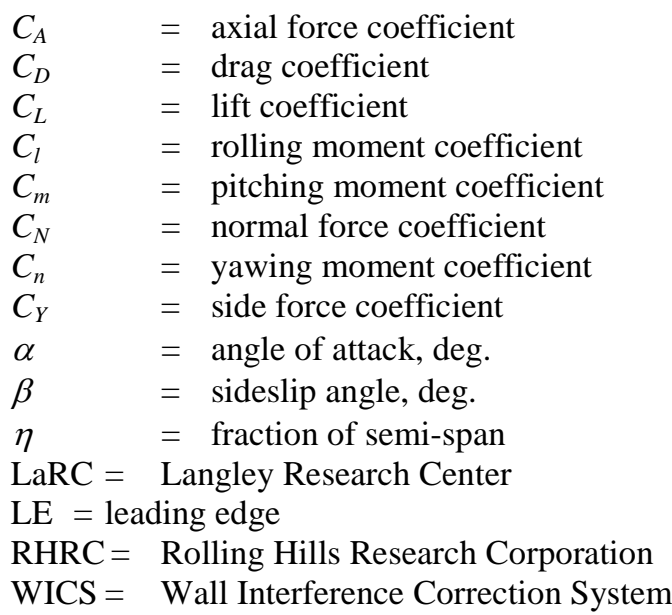

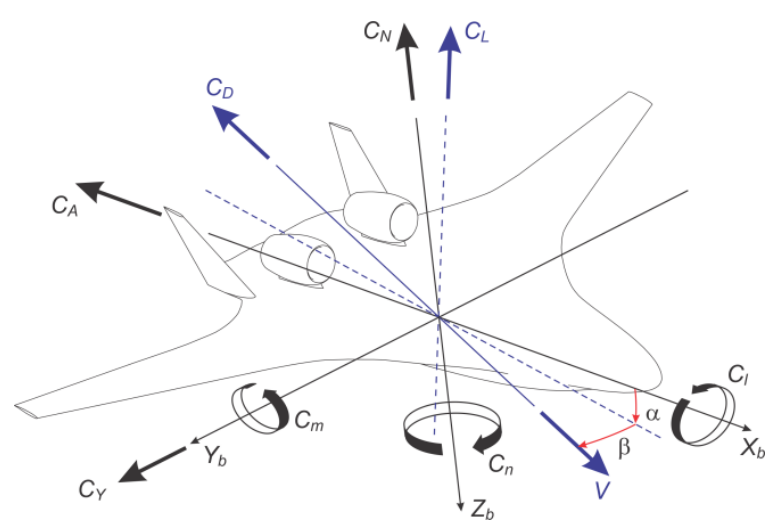

Figure 1. Axes with force and moment orientation.

\section{Introduction}

A series of low-speed experimental investigations have been conducted on a Hybrid Wing Body (HWB) twin-jet configuration. This HWB configuration, shown in figure 2, incorporates twin, podded nacelles mounted on the vehicle upper surface between twin vertical tails. The configuration was developed through a NASA Research Announcement (NRA) lead by The Boeing Company entitled "Acoustic Prediction Methodology and Test Validation for an Efficient Low-Noise Hybrid Wing Body Subsonic Transport.” This NRA included a task to develop a conceptual design of an HWB configuration that would meet the NASA Environmentally Responsible Aviation (ERA) $\mathrm{N}+2$ goals starting from the Cambridge-MIT Institute Silent Aircraft Initiative SAX-40 configuration. ${ }^{1}$ The resultant configuration was designated the HWB-N2A. In general, the basic goals of the NRA were to:

1) Develop an HWB configuration capable of meeting the reduced noise and reduced fuel burn goals.

\footnotetext{
${ }^{1}$ Senior Research Engineer, Flight Dynamics Branch, MS 308, AIAA Associate Fellow.

${ }^{2}$ Research Engineer, Configuration Aerodynamics Branch, MS 267, AIAA Senior Member.

${ }^{3}$ Research Scientist, Flow Physics and Control Branch, MS 170.

${ }^{4}$ Senior Research Engineer, Dynamic Systems \& Control Branch, MS 308, AIAA Associate Fellow.

${ }^{5}$ Research Engineer, Configuration Aerodynamics Branch, MS499, AIAA Senior Member.
} 


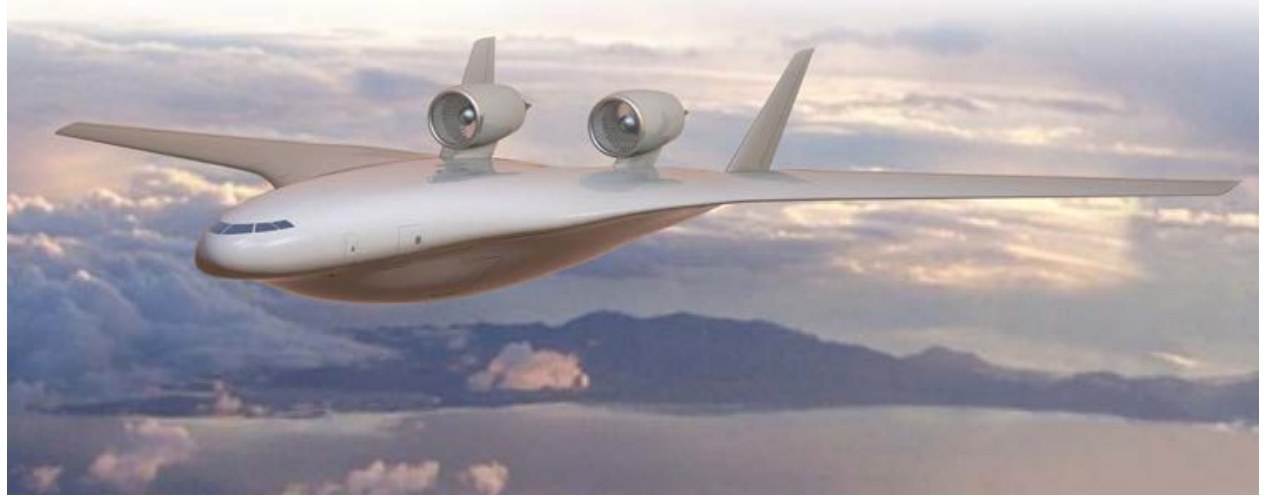

Figure 2. Illustration of full-scale HWB configuration.

2) Develop improved noise prediction methods for this type of configuration.

3) Design and fabricate a wind tunnel model for use in validating predictions.

4) Assess the low-speed aerodynamic characteristics of the configuration developed.

It is this last item that is addressed via the wind tunnel, CFD, and water tunnel investigations reported on in this paper. The NRA and the subsequent wind tunnel investigations were supported and funded by the ERA project ${ }^{2-8}$ within the Integrated Systems Research Program (ISRP). Three wind tunnel tests were conducted in the NASA Langley 14- by 22-Foot Subsonic Tunnel on the 5.8-percent scale model shown in figure 3. The first test focused on measuring the basic low-speed aerodynamics ${ }^{9}$ while the second was an acoustics test. ${ }^{10-12}$ The third test focused on characterizing the nacelle inlet flow conditions through particle image velocimetry (PIV) measurements. The acoustic test results will not be covered in this paper, only the low-speed aerodynamic tests. The model was installed and tested as shown in figure 3 for both aerodynamic tests.

The HWB water tunnel test was funded through a NASA Small Business Innovative Research (SBIR) award to Rolling Hills Research. ${ }^{13}$ The primary objective of this test was to explore new dynamic test techniques and modeling methodologies. ${ }^{14}$ A series of dye port flow visualizations was also conducted in support of the wind tunnel tests. An example is shown in figure 4. Only static dye port flow visualizations will be discussed in this paper.

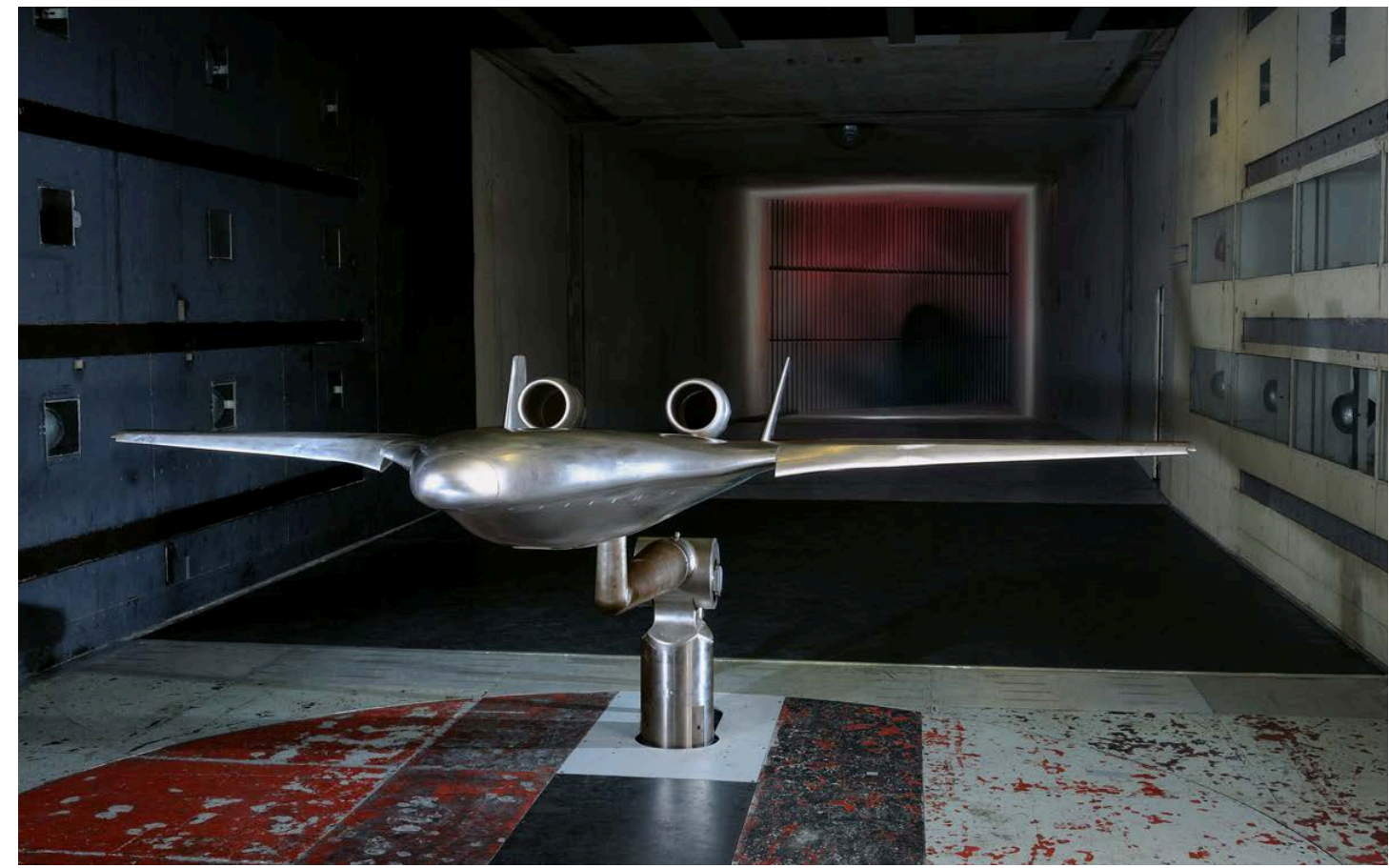

Figure 3. The 5.8-percent scale HWB model in the NASA Langley 14- by 22-Foot Subsonic Tunnel.

American Institute of Aeronautics and Astronautics 


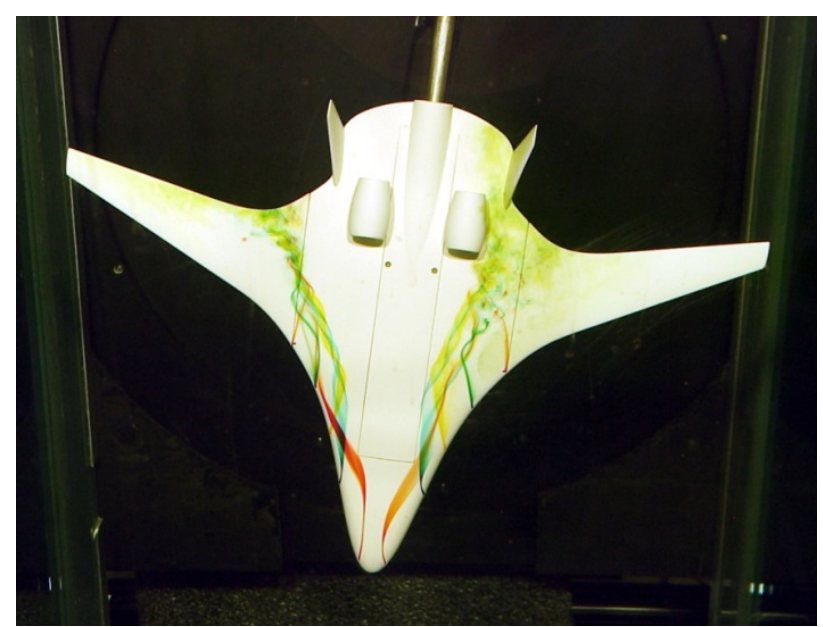

Figure 4. The 0.7-percent scale HWB model in the Rolling Hills water tunnel $\left(\alpha=10^{\circ}, \beta=-7.5^{\circ}\right)$.

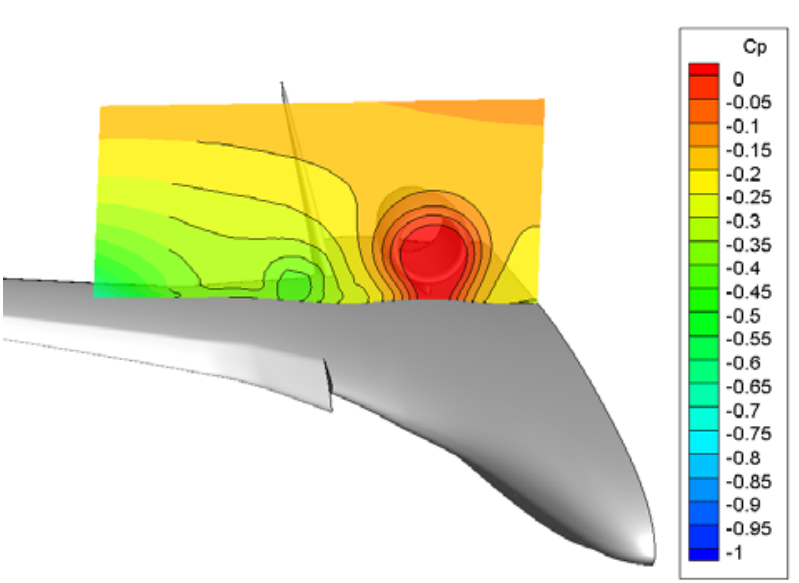

Figure 5. CFD off-body pressure contour $\left(\alpha=16^{\circ}\right)$.

In addition to the wind tunnel and water tunnel tests, a limited set of computational fluid dynamics (CFD) predictions was also performed. The CFD predictions supported the off-body nacelle inlet flow analysis, an example of which is shown in figure 5.

This paper will compare and summarize some of the interesting findings from these tests and highlight the extent of the data that is openly available for code validation or additional analysis of this HWB configuration.

\section{Experimental Approach}

\section{A. NASA Langley 14- by 22-Foot Low-speed Tunnel Tests}

Two aerodynamic tests and one acoustic test were conducted on the HWB-N2A configuration in the NASA Langley 14- by 22-Foot Subsonic Tunnel. This tunnel is an atmospheric, closed circuit facility, with a test section that can be operated in an open (side walls and ceiling raised) or closed configuration. ${ }^{15}$ The test section dimensions in the closed configuration are 14.5 feet high by 21.75 feet wide by 50 feet long. Figure 3 shows the model in the tunnel with the walls and ceiling in the closed configuration. Most of the first aerodynamic test was conducted in the closed configuration, whereas all of the second was conducted in the open configuration allowing for greater optical access for the PIV measurements.

The wind tunnel model is a 5.8\% scale HWB-N2A configuration with a span of 12.354 feet (Fig. 6). The model included two leading edge configurations; an undeflected cruise leading edge and a drooped leading edge for high lift. The drooped leading edge begins at $\eta=0.311$ and is deflected 20 degrees down from there to $\eta=0.4$. The droop then transitions to 30 degrees down from $\eta=0.4$ to $\eta=0.445$ and is maintained at 30 degrees for the remainder of the span. The sweep angle at the quarter-chord of the constant sweep, outboard portion of the wing, is 24.2 degrees. The model moment reference center is located at 53.94percent of the fuselage length aft of the model nose corresponding to 38.64-percent of the mean aerodynamic chord. The model reference area is $33.499 \mathrm{ft}^{2}$, and the reference chord is 60.552 inches.

In addition to the cruise and drooped leading edges, the other variable geometry features of the model included three longitudinal mounting positions for the flow-through nacelles; alternate

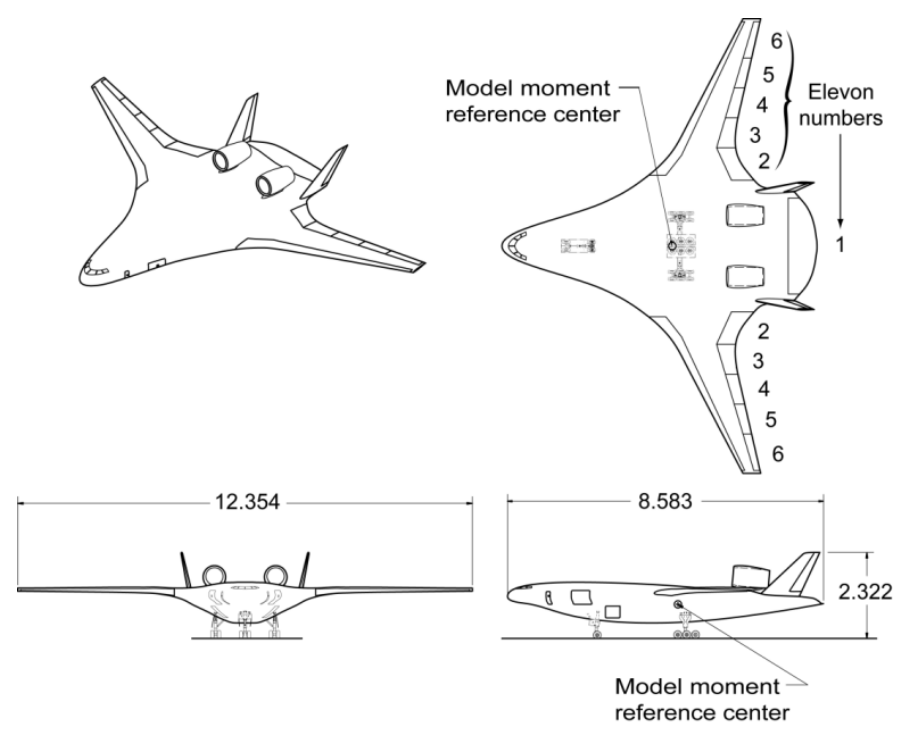

Figure 6. Three-view sketch of HWB model. (Dimensions in feet) 
lower aspect ratio vertical tails, two vertical tail longitudinal mounting locations, two vertical tail cant angles, deflectable control surfaces, and landing gear. The effects of these geometry changes are explored in reference 9. The data presented throughout this paper is for the nacelles at the mid location, the higher aspect ratio vertical tails mounted with a $10^{\circ}$ cant angle at the aft location, all elevons and rudders undeflected, and the landing gear off. The only geometry variation presented in this paper will be the drooped or cruise leading edge.

The model was also equipped with an array of upper and lower surface pressure taps provided in chordwise rows at four span locations. These pressure tap rows are located on the left side of the model at semi-span stations of 13.4, 30.5, 51.0, and 90.6-percent.

\section{B. Wind Tunnel Test Conditions}

The primary objective of the first wind tunnel test (Test 597) conducted in the summer of 2011 was to obtain the basic longitudinal and lateral/directional aerodynamic characteristics of the configuration along with some limited control effectiveness measurements. Force, moment, and surface pressure data were obtained across an angle of attack range of from -12 to +36 degrees. Some sideslip sweeps were also conducted from -30 to +30 degrees. Highlighted results of this test were reported in reference 9 .

The majority of the test was conducted with the walls and ceiling down (closed test section) at a free stream dynamic pressure of $60 \mathrm{psf}$ (Mach $=0.20$ ). Due to the rather large size and unconventional shape of the HWB configuration, the wall pressure signature correction method was selected to correct for wall and blockage effects. The Wall Interference Correction System ${ }^{16}$ (WICS) is the wall pressure signature correction method employed at the 14- by 22-Foot Subsonic Tunnel. Wall corrections are applied to free stream dynamic pressure, angle of attack, and force and moment coefficients. Flow angularity measurements were not obtained for this model, thus up-flow corrections were not applied.

Surface flow visualization data were obtained for angles of attack from 11 to 18 degrees. A mineral oil designed for use in aviation engines was mixed with alcohol and sprayed on the model using a hand held, shop air driven paint sprayer. The oil is manufactured with a fluorescent dye, which glowed brightly when illuminated with ultraviolet lights located in the ceiling of the wind tunnel. After the oil mixture was sprayed on the model, and the tunnel was run for several minutes to establish the surface flow pattern, photographs were taken while on test condition through a window in the tunnel ceiling. Since many pressure taps were located in the left wing, the surface flow visualization was set up to capture images emphasizing the right side of the model. An example is shown in figure 7.

The objective of the second aerodynamic test (Test 612) conducted in the fall of 2013 was to explore the use of PIV to characterize the upper-surface aft-body aerodynamics near the nacelle inlet at various angle-of-attack and sideslip values. This test was also conducted at a free stream dynamic pressure of $60 \mathrm{psf}$ but with the walls and ceiling raised (open test section) to provide greater optical access for the PIV system. The upper surface of the model was also painted black to reduce the PIV laser system reflections.

Test 597 used transition grit applied to the model to fix the transition of the boundary layer from laminar to turbulent in a consistent and repeatable manner. Grit height and application were guided by the methods presented in reference 17 , as well as by common practices used in the 14- by 22-Foot Subsonic Tunnel. The grit was applied in a ring around the nose of the model at a model station 3 inches aft of the most forward point on the fuselage. Along the length of the fore body, transition grit was placed 3 inches aft of the leading edge on the upper surface and 2.5 inches aft on the lower surface. On the wings, transition grit was placed 1.7 inches aft of the leading edge on both the upper and lower surfaces. Transition grit was also placed 1.7 inches aft of the leading edge on both surfaces of the nacelles, pylons, and vertical tails. All distances aft of the leading edges were measured

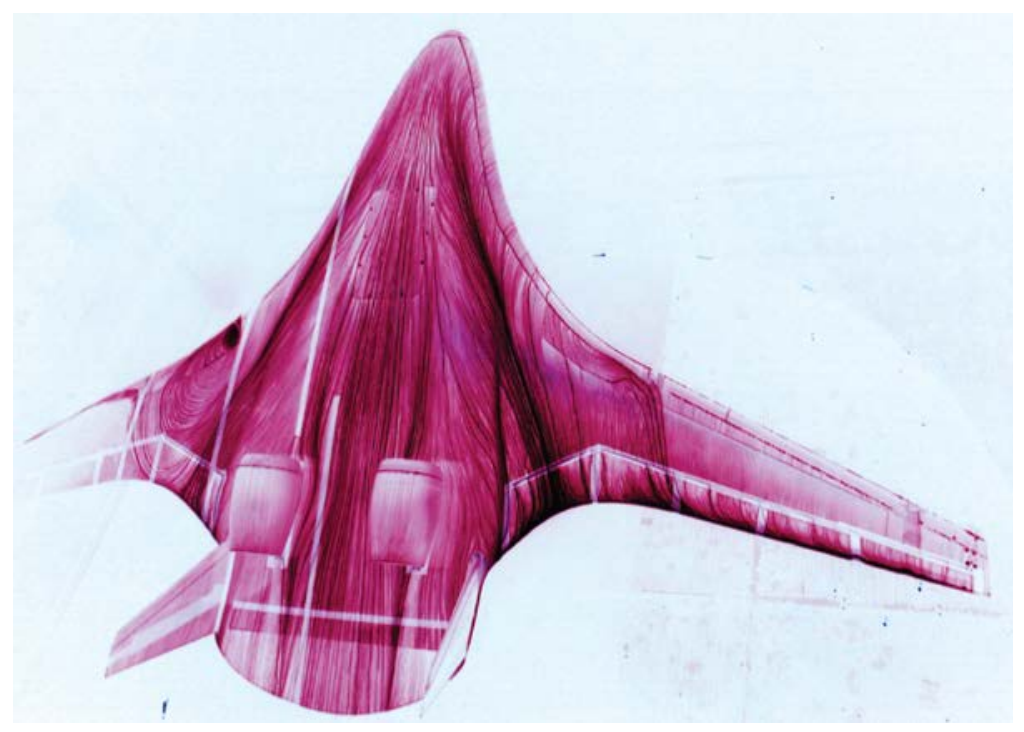

Figure 7. Surface flow visualization $\left(\alpha=13^{\circ}, \beta=0^{\circ}\right)$. 4

American Institute of Aeronautics and Astronautics 


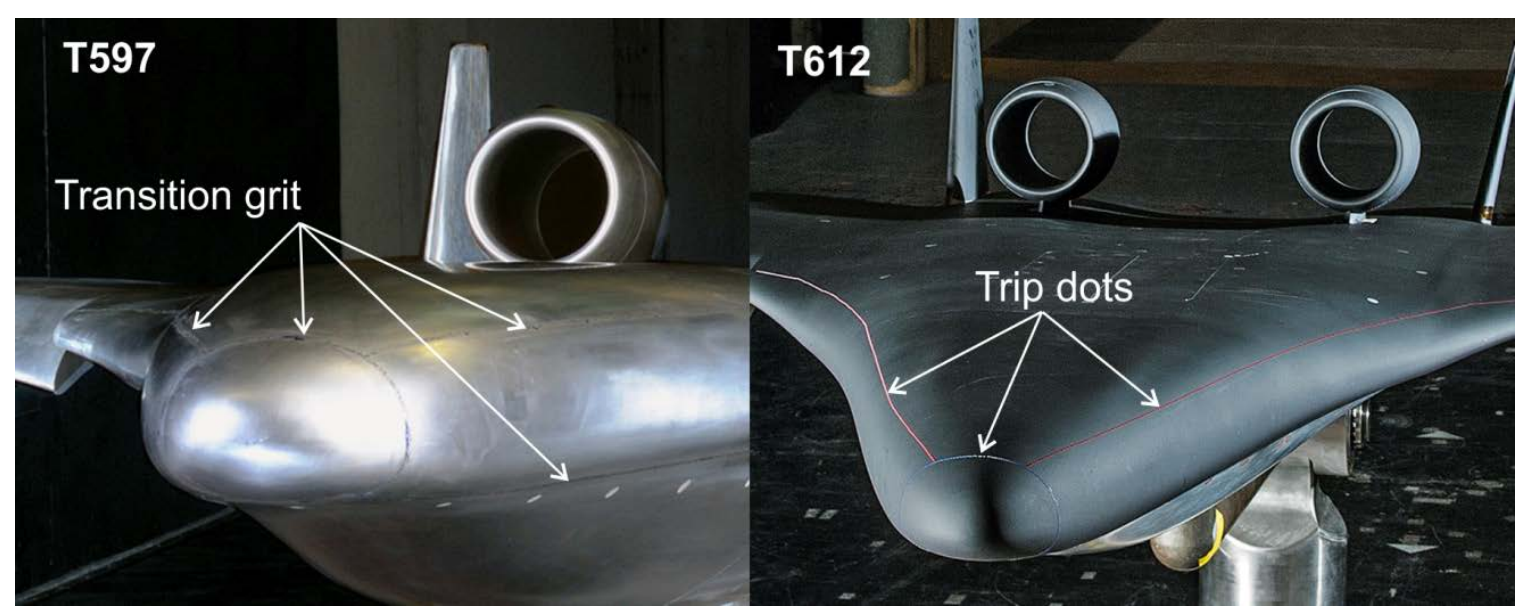

Figure 8. Boundary layer transition grit and trip dots.

perpendicular to the leading edge and along the model surface. Test 612 used trip dots rather than grit along the same locations and height as the grit from the previous test, as shown in figure 8.

\section{Particle Image Velocimetry (PIV) Measurements}

Test 612 focused on demonstrating the capability of particle image velocimetry (PIV) to measure the off-surface flow field and capture pertinent features such as the flow conditions near the nacelle inlet and the vortical flow on the upper surface. Vortex size and location are important parameters for validating CFD methods used to predict vortical flow separation on wing-body configurations with rounded leading edges.

Over the past seven years, stereo PIV (SPIV) systems have proven to be a valid and efficient tool to document flow fields in the 14x22 for both fixed-wing and rotary-wing configurations. The main challenge in this experiment was to configure the SPIV systems to measure the flow field close to the nacelle inlet without saturating the surface with laser light and obscuring meaningful data. An SPIV system (System 1) comprised of two, 11 megapixel CCD

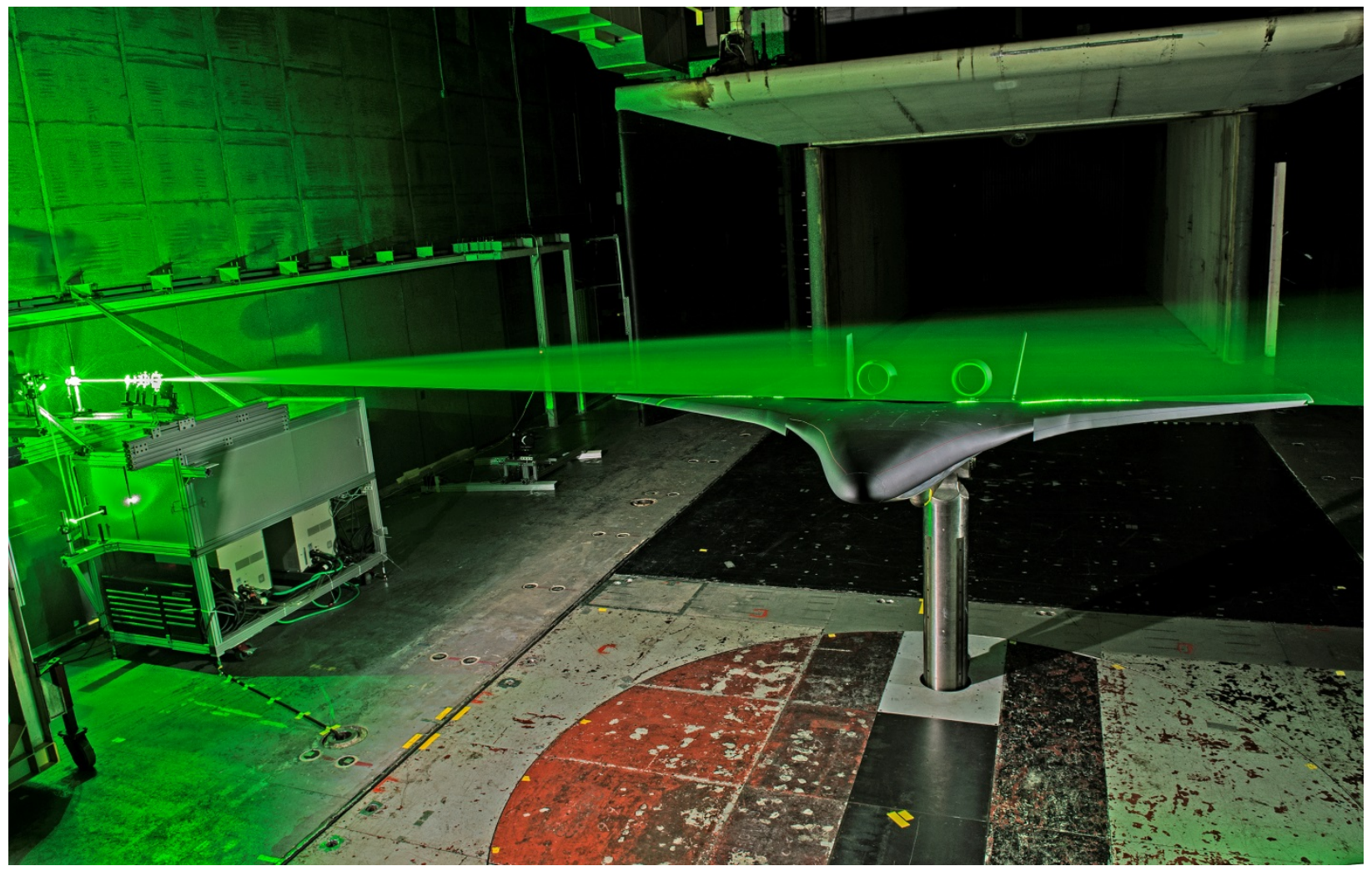

Figure 9. PIV laser sheet projected across the model in the tunnel test section.

American Institute of Aeronautics and Astronautics 
cameras equipped with 400 millimeter lenses and two 1.5 Joule Nd-YAG lasers was used to capture the velocity field near the nacelle inlet. The cameras were mounted upstream of the model, one on each side of the tunnel, and the laser light sheet was projected across the top of the model from the right which required one camera to operate in forward scatter and the other camera to operate in backscatter mode. The orientation of the laser light sheet with respect to the model is shown in Figure 9. When possible, it is preferable to have both cameras in forward scatter to obtain the highest signal-to-noise ratio. Unfortunately, using such an arrangement in this case would result in the view of one of the cameras being partially blocked by the nacelle and tail. At the operating distance of 24 feet, this camera/lens combination provided a field of view (FOV) 35 inches wide and 17 inches high which was large enough to capture the flow in front of the right nacelle and over a small segment of the right wing.

A second SPIV system (System 2) comprised of two, 4 megapixel cameras equipped with 600 millimeter lenses and a 200 milliJoule laser was used to measure the velocity field near the leading edge. At the operating distance of 22 feet, this arrangement provided a FOV approximately 7 inches wide and 4 inches high that was adequate to capture the leading edge vortex in its formative stages. Both cameras were mounted on the right side of the model and the laser light sheet was projected across the model from the left, putting the cameras in forward scatter. In this configuration, blockage from the nacelle or tail was not a problem but at certain angles of attack and model heights, a small region at the bottom of the camera images was clipped by the leading or trailing edge of the wing. While this was beneficial in that it prevented the cameras from seeing optical flaring off of the model, it also limited how close data could be obtained near the surface.

For both systems, the cameras and laser light sheet were rotated to an angle of 16 degrees to make the measurement plane normal to the waterline when the model was at an angle of attack of 16 degrees. This angle was maintained for the other angles of attack; however the velocity components were rotated to be consistent with the model coordinate system. Seed particles were introduced into the flow using a commercial fog machine with a mineral oil based mixture. The fog machine was located in the rear of the test section and, at specific intervals, ejected polydispersed particles ranging in diameter from 0.25 microns to 1.5 microns into the diffuser. The particles then passed through the fan and the return leg of the tunnel before entering the test section

The dataset includes velocity fields measured in three crossflow planes at angles of attack of 16, 18, and 20 degrees and sideslip angles of 5, 10, and 15 degrees. A minimum of 100 images were acquired for each angle of attack/sideslip angle combination. The PIV images were processed using an interrogation area of 64 pixels by 64 pixels with 50\% overlap for System 1 and an area of 24 pixels by 24 pixels with $50 \%$ overlap for System 2 . These settings correspond to a spatial resolution of $10 \mathrm{~mm}$ by $10 \mathrm{~mm}$ for System 1 and $1.9 \mathrm{~mm}$ by $1.9 \mathrm{~mm}$ for System 2 .

\section{Rolling Hills Research Corporation Water Tunnel Test}

The water tunnel test was conducted in the Rolling Hills Research Corporation research water tunnel Model 2436. This tunnel has a 24" high, 36" wide, and 72" long test section with a 3-axis computer controlled model support system capable of either static or multi-degree of freedom dynamic testing. The model was a $0.7 \%$ scale HWB-N2A configuration with a span of approximately 18 inches. The model included dye ports for flow visualization along the leading edge of the nose and center-body. The model was aft-sting mounted with a 5-component (no axial force measurement) internal balance. The balance moment center was co-located with the model moment reference center at 38.64-percent of the mean aerodynamic chord. The clearance required for the aft sting mounting arrangement resulted in a cylindrical bump in the aft center body loft as can be seen in figure 4 . This was the only geometry difference between the water tunnel and wind tunnel models. The water tunnel testing was conducted at a velocity of 11 inches per second, corresponding to a chord Reynolds Number of $5.8 \times 10^{4}$. 


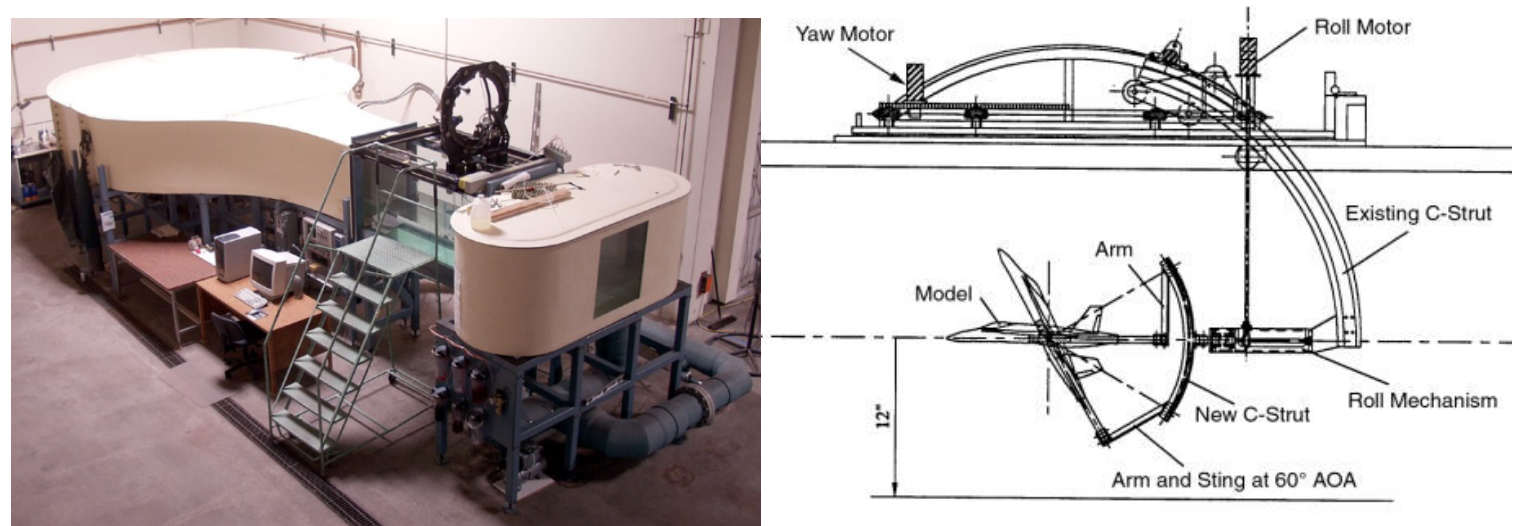

Figure 10. Rolling Hills Model 2436 water tunnel and 3-axis model support system.

\section{Computational Approach}

Only a limited set of CFD runs was conducted with the selected cases focusing on matching the PIV test conditions. The analysis used the TertUSS ${ }^{18}$ suite of CFD codes that was created and is maintained by NASA Langley Research Center. These codes include an unstructured grid generation program called VGRID, a postprocessor named POSTGRID, and the flow solver USM3D.

VGRID is an interactive, or batch, tetrahedral unstructured grid generation program. The grids produced by VGRID are suitable for computing Euler or Navier-Stokes flow solutions. The grid spacing is related to the strength of user-defined sources placed in the domain. The methodology is based on the Advancing-Front method ${ }^{19}$ and the Advancing-Layers method. ${ }^{20}$ Both techniques are based on marching processes in which tetrahedral cells grow on an initial triangular boundary mesh and gradually form in the field around the geometry. Once the advancing front process is completed in VGRID, an additional post-processing step is required using POSTGRID to close any open pockets and to improve grid quality.

The USM3D code $^{21}$ is a cell-centered, finite-volume Navier-Stokes flow solver that uses Roe flux-difference splitting to compute inviscid flux quantities across the faces of the tetrahedral cells. ${ }^{22}$ Several options for turbulent closure are available: the one-equation Spalart-Allmaras (S-A) model ${ }^{23}$ (with and without a wall function), and several two-equation models, including Menter's Shear Stress Transport (SST) model ${ }^{24}$ and the linear k-epsilon turbulence model. ${ }^{25}$ This study used both the k-epsilon and SST models.

Several grids were generated to assure grid convergence. Pre-test predictions were generated with a grid of approximately 79.1 million cells and using the k-epsilon turbulence model. The final grid produced, which was approximately 115 million grid cells, was run using the SST turbulence model in both steady and unsteady state runs. Different turbulence models and conditions (unsteady) were tried in an effort to better match the experimental results.

All of the computational data was run at Mach 0.20 , angle of attack of 16 -degrees, $550{ }^{\circ} \mathrm{R}$ temperature and a chord Reynolds number of 6.5 million.

\section{Results and Discussion}

The effect of geometry changes such as nacelle or fin location and control surface deflections have been previously documented in reference 9 and will not be repeated here. The focus of this paper is on comparing and highlighting the results of the various tests, measurements and computations conducted on this non-proprietary HWB configuration.

\section{E. Wind Tunnel Results}

As previously noted there were two wind tunnel tests conducted with the 5.8\% scale model. Most of the first test (T597) was conducted with a closed test section whereas all of the second (T612) was conducted with an open test section. Consequently, there are only a couple of runs that are directly comparable between the two tests. Figure 11 shows a test-to-test comparison of the longitudinal coefficients for the model with the drooped leading edge. The pre-stall repeatability in lift and pitching moment appears very good with about 10 counts of drag difference between the tests. This drag difference as well as the post-stall differences could be due to the difference between the transition grit used in T597 and the trip dots used in T612. 
The difference between open and closed test section measurements is illustrated in figures 12 and 13 . Also shown in the figures are the WICS code corrected data from the wall pressure measurements. These runs are all from test T597. The magnitude of lift and drag values of the open test section data, for both leading edge configurations, are slightly lower than the closed test section data. This is indicative of a dynamic pressure shift between the open and closed test section that is not being accounted for. This difference is not generally noted in the facility since most testing is conducted in either open or closed configuration, but rarely both.
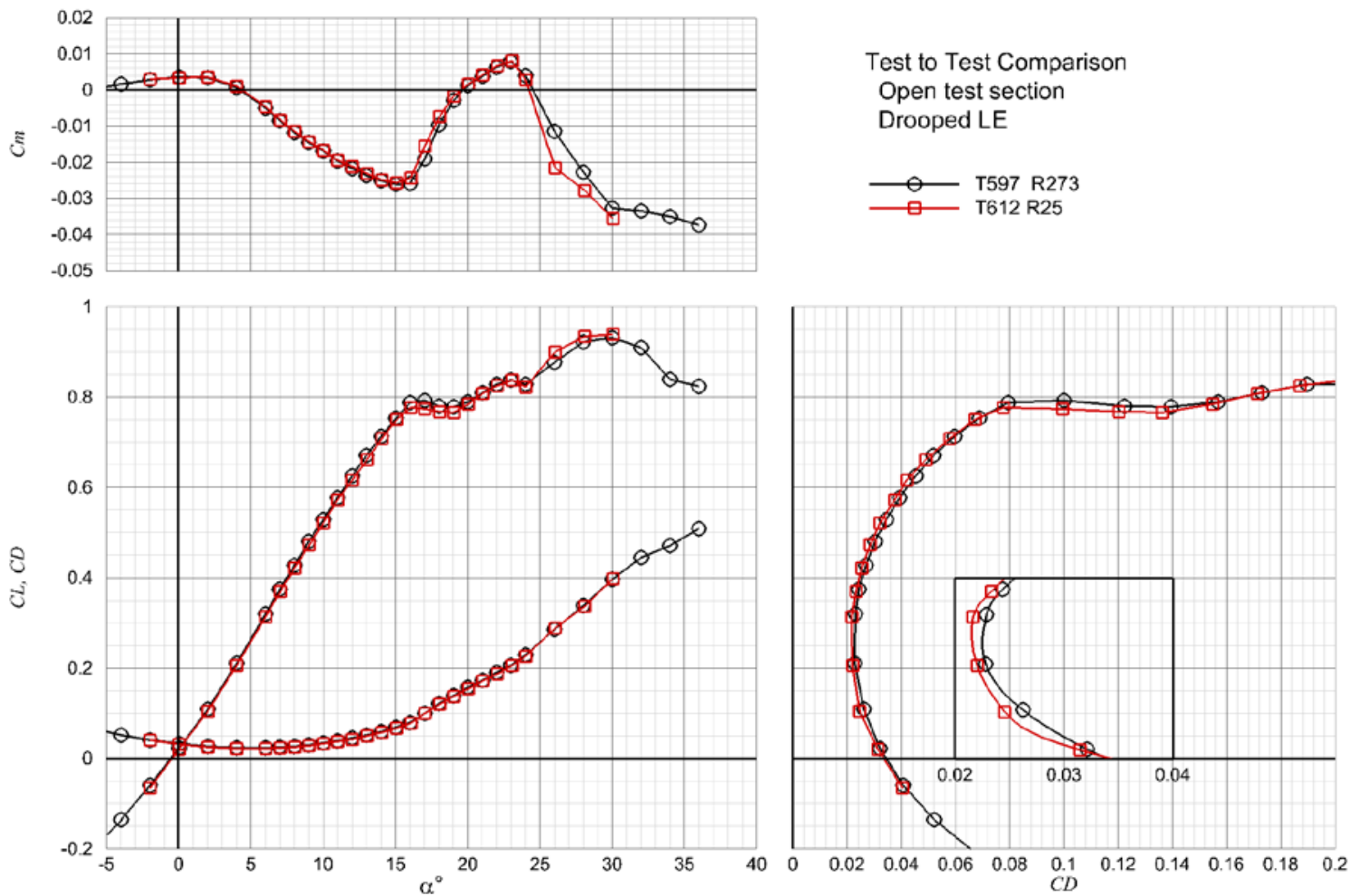

Figure 11. Wind tunnel test to test comparison of longitudinal coefficient measurements. 


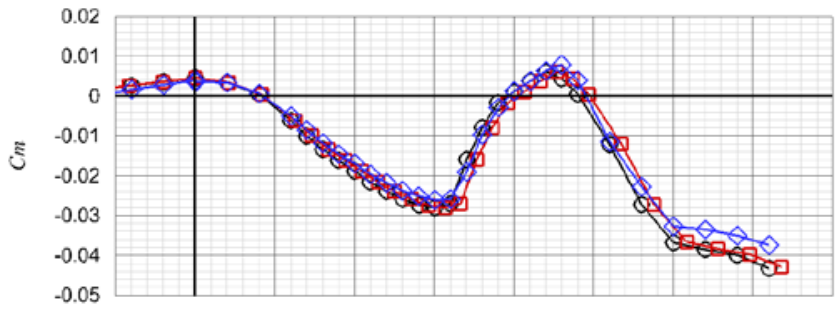
Open vs Closed Test Section Comparison
Drooped LE
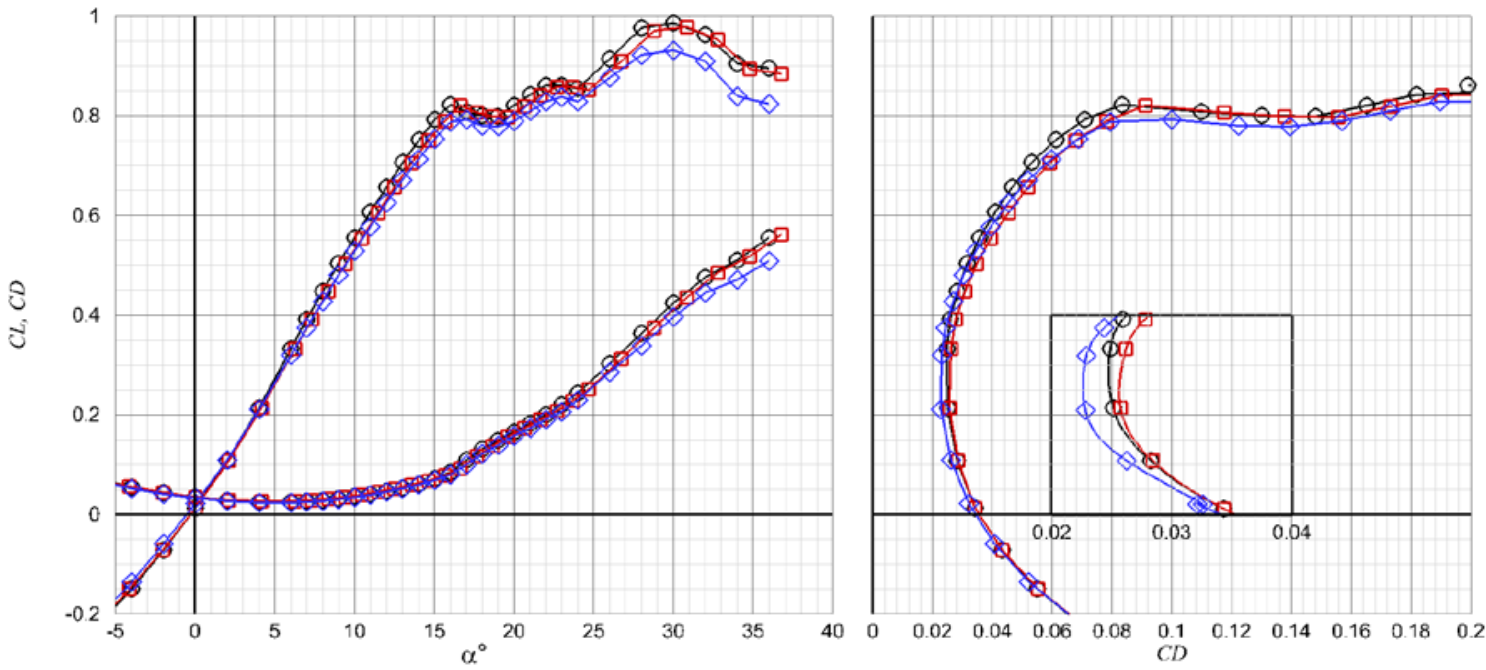

Figure 12. Comparison of open vs. closed test section and the effect of WICS wall corrections for the drooped LE configuration.

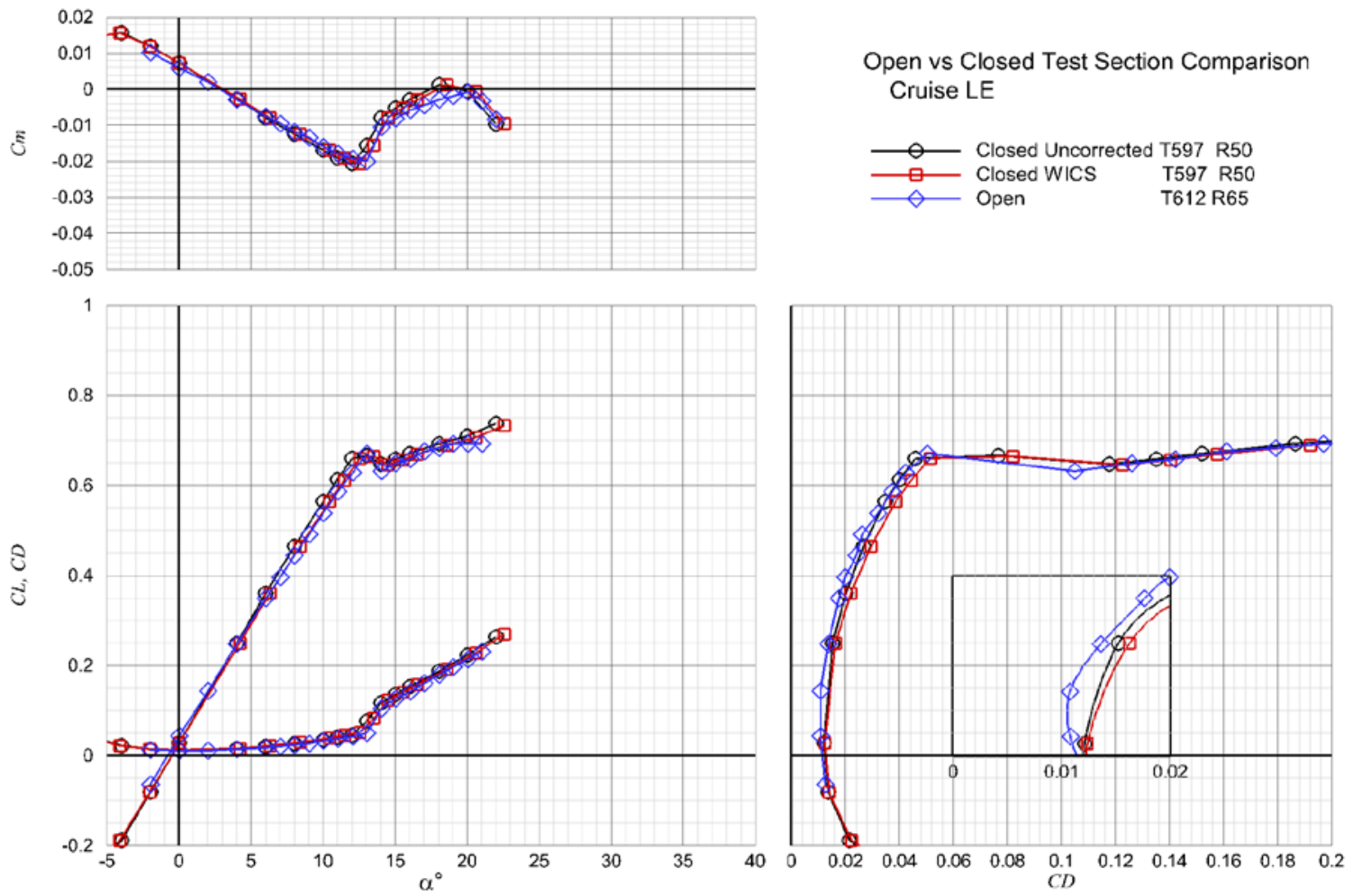

Figure 13. Comparison of open vs. closed test section and the effect of WICS wall corrections for the cruise LE configuration.

American Institute of Aeronautics and Astronautics 


\section{F. Water Tunnel Comparison}

The primary objective of the water tunnel test was to explore new dynamic test techniques and modeling methods. The water tunnel provides a low cost test environment and the low Reynolds numbers inherent in water tunnel testing did not negatively impact this primary research objective ${ }^{14}$. A secondary objective of this test was to use the water tunnel flow visualization capability to explore potential interactions between vortices shed from the center body and the nacelle inlets. A series of dye ports along the leading edge of the nose and center body enable the flow visualization. Unfortunately, there were no flow visualization runs completed for the drooped leading edge configuration.

The matrix of flow visualization results for the cruise leading edge is shown in figure 14. A leading edge vortex roll-up can be seen at $10^{\circ}$ and $15^{\circ}$ angle of attack but remains outboard of the nacelles at $0^{\circ}$ of sideslip. As is typical the vortex burst location moves upstream as the angle of attack in increased. At the higher sideslip values the leading edge vortex moves closer to the windward nacelle but appears to have burst or the flow has separated upstream of the nacelle. Of course, vortex burst locations and flow separations are very Reynolds number dependent flow features.

Comparison of the water tunnel and wind tunnel normal force and pitching moment measurements, shown in figure 15, provides some additional insight. There appeared to be a constant angle of attack and pitching moment shift between the water and wind tunnel data sets. This offset $\left(\Delta \alpha=1.5^{\circ}, \Delta C_{m}=0.014\right)$ was applied to the water tunnel data and is plotted as the blue data in the figure. The figure clearly shows the separation occurring about $7^{\circ}$ earlier for the cruise leading edge to $10^{\circ}$ earlier for the drooped leading edge in the water tunnel with a Reynolds number of $5.8 \times 10^{4}$ relative to the wind tunnel, with a Reynolds number of 6.5 million. 

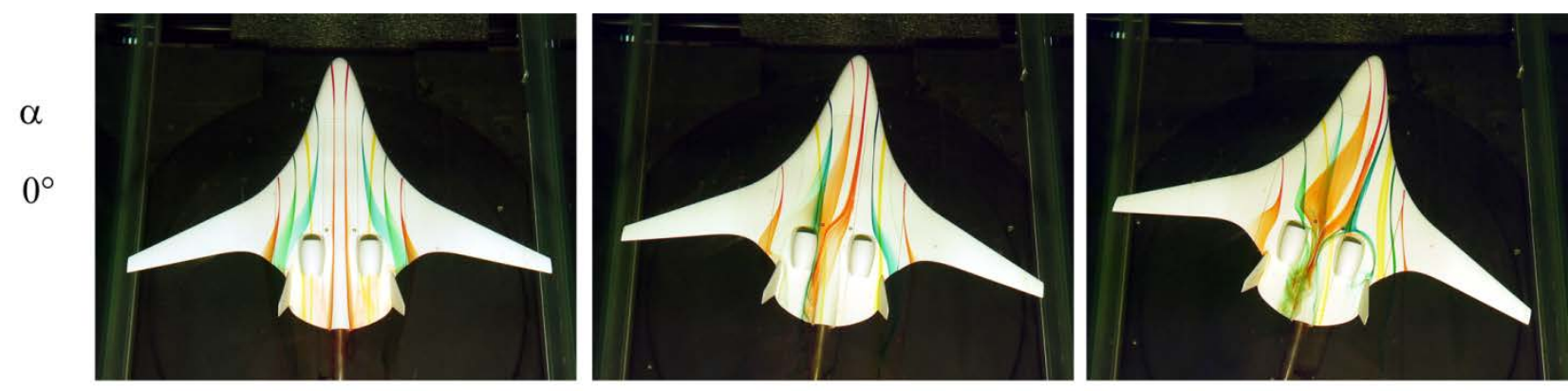

$5^{\circ}$
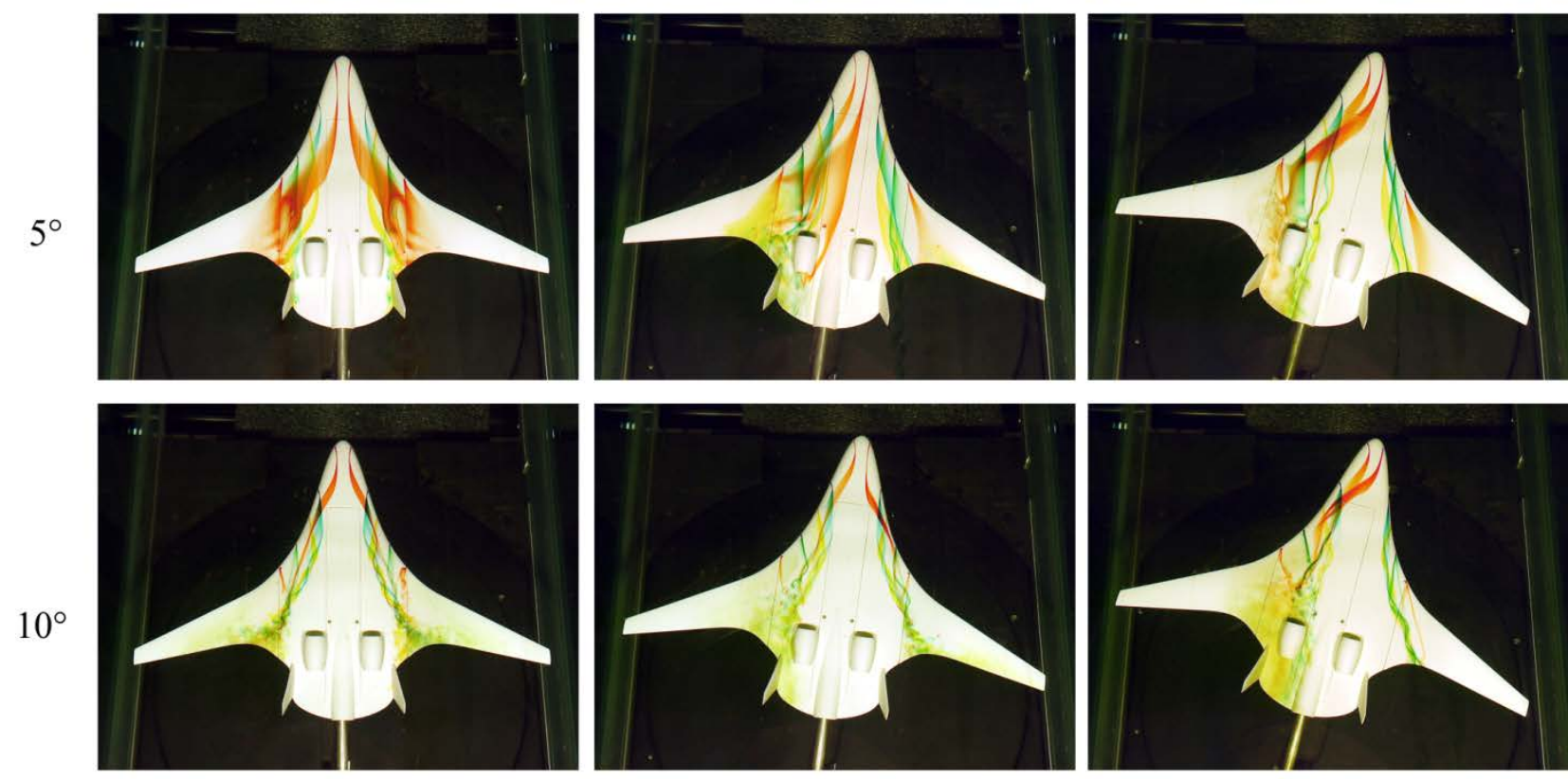

$15^{\circ}$

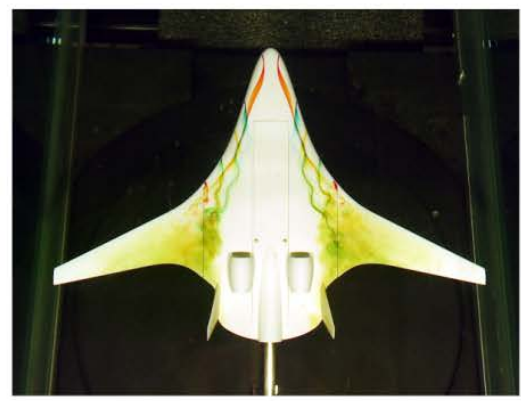

$\beta=0^{\circ}$

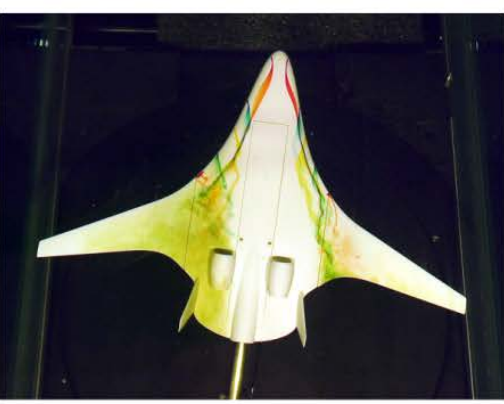

$-7.5^{\circ}$

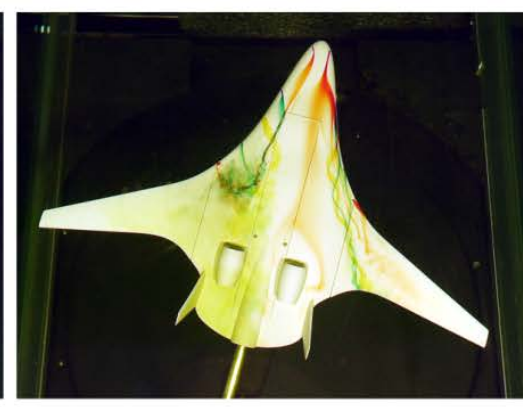

$-15^{\circ}$

Figure 14. Water tunnel flow visualization matrix for cruise leading edge. 

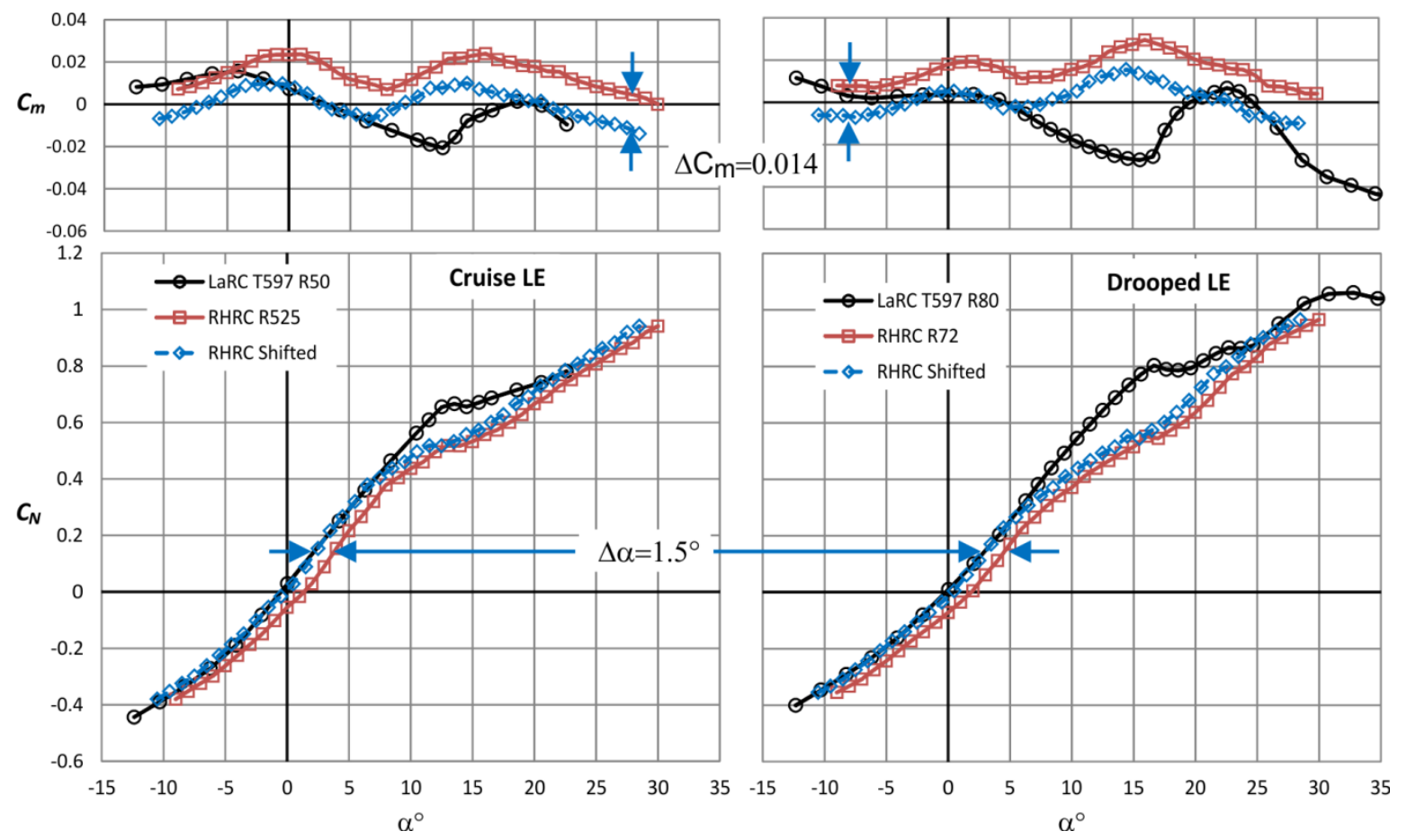

Figure 15. Wind tunnel and water tunnel normal force and pitching moment comparison.

\section{G. CFD Comparison}

Comparison of the USM3D integrated force and moment predictions with the wind tunnel measurements are presented in figures 16 thru 18. The wind tunnel measurements presented in figures 16 and 17 show both the open and closed test section measurements, with the closed test section data including the WICS wall corrections. There are also two sets of CFD predictions. One set labeled "Free Air" includes only the model in the calculations whereas the second set included the model support and the tunnel walls in the calculation. In general, the CFD matches the tunnel measurements fairy well with the largest outlier being the pitching moment prediction for the drooped leading at $24^{\circ}$ angle of attack. The CFD also tended to over-predict the drag by about 80 to 100 counts in the linear angle of attack range. The limited set of USM3D results that include the support and wall effects matched the tunnel measurements better than the "free air" solutions. These results along with the measurement variations seen in the open and closed test section data presented in figures 12 and 13 highlight the need for improved methods to correct for wind tunnel installation effects.

Comparisons of the force and moment predictions with sideslip angle are shown in figure 18 for the drooped leading edge configuration at $16^{\circ}$ angle of attack. The CFD show good agreement with the measured coefficients up to $5^{\circ}$ of sideslip. As previously noted, the drag was over predicted by about 90 counts. Above $5^{\circ}$ of sideslip, the CFD appears to have over predicted the separation as evidenced by the increased drag and under prediction of lift and rolling moment. Predicting the separation on a highly swept curved surface such as the center body of this HWB is a challenging problem for many CFD codes and warrants further investigation. 


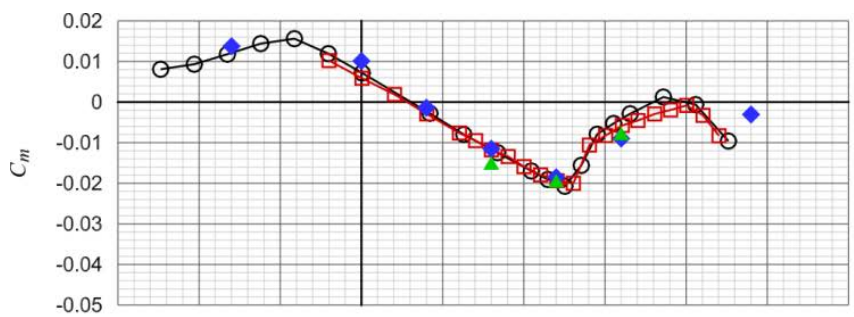

Wind Tunnel and CFD Comparison Cruise LE
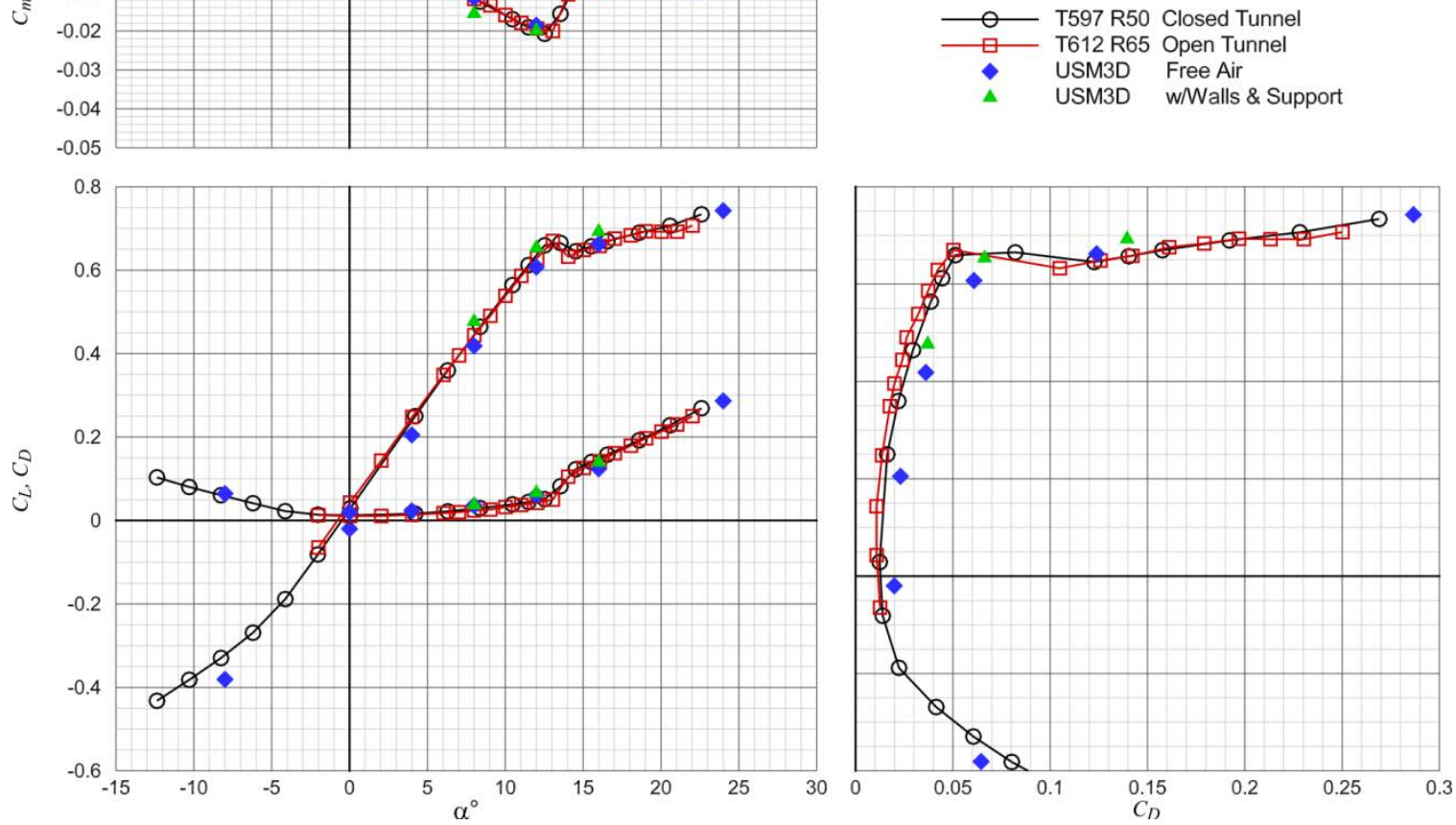

Figure 16. Comparison of CFD and wind tunnel data for cruise leading edge configuration $(\beta=09)$.

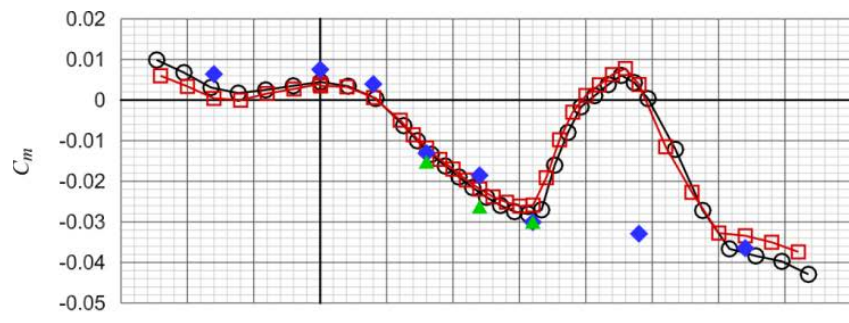

\section{Wind Tunnel and CFD Comparison Drooped LE}
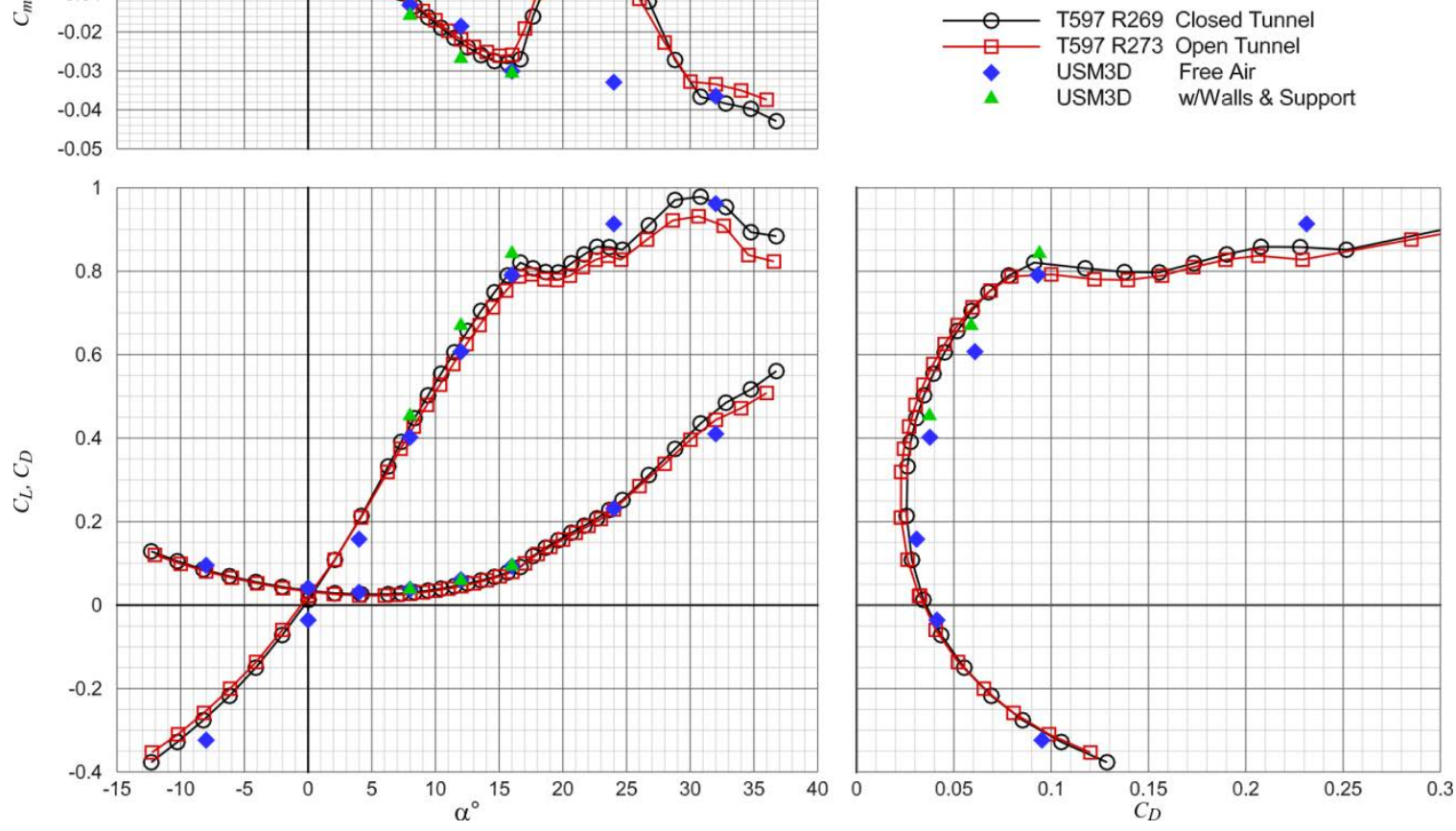

Figure 17. Comparison of CFD and wind tunnel data for drooped leading edge configuration $(\beta=0)$. 

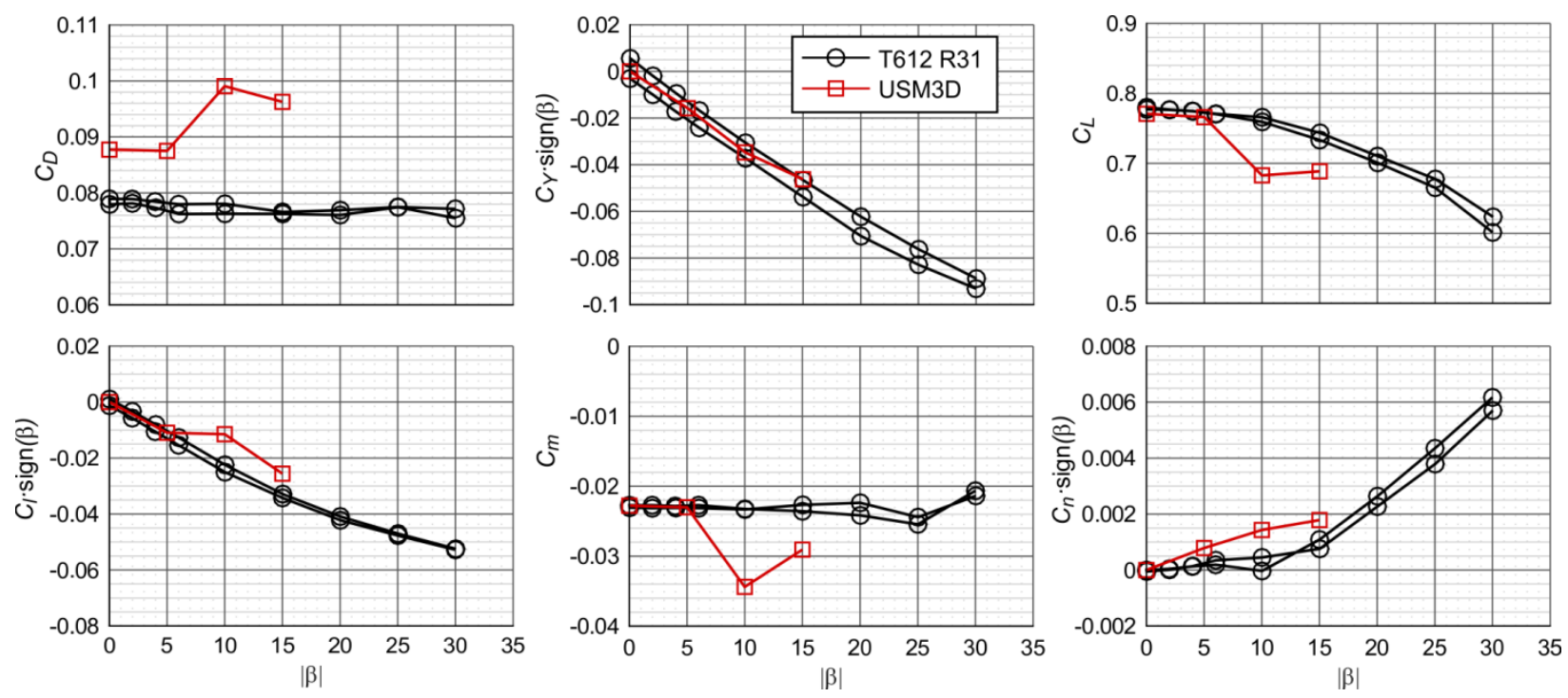

Figure 18. Comparison of CFD and wind tunnel data for drooped leading edge configuration $(\alpha=169$.

\section{H. Surface Flow Visualization}

A surface oil flow visualization technique using fluorescent oil and ultra violet lights was used in T597 to produce images of surface flow patterns. Several of these images are presented and analyzed in reference 9. Figure 19 shows a comparison of an oil flow image at $15.6^{\circ}$ angle of attack with USM3D surface streaklines computed at $16^{\circ}$ angle of attack. Both images show a separation region just inboard of the drooped leading edge break. The oil flow also shows evidence of multiple vortex systems scrubbing the upper surface. These vortices are emanating from the center body leading edge as well as the inboard drooped leading edge. The CFD streaklines also show the inboard drooped leading edge vortex but less evidence of other center-body vortices.

\section{PIV Measurements}

The primary objective of the second wind tunnel test (T612) was to explore the potential of PIV to measure the nacelle inlet flow conditions. The PIV measurements were taken at several longitudinal locations along the center body for various angles of attack and sideslip. In figure 20, contours of velocity magnitude show the off-body flow features captured by PIV and CFD for an angle of attack of 16 degrees and sideslip angle of 0 degrees. Overall, the measurements and simulations compare quite well: both show a velocity deficit at the nacelle inlet as well as the leading edge vortex. The size and location of the vortex are similar but there are some subtle differences outboard and inboard of the vortex near the surface. The CFD results show a continuous region of low velocity fluid whereas in the middle plane, the PIV shows discrete regions. Another difference can be seen in front of the nacelle where

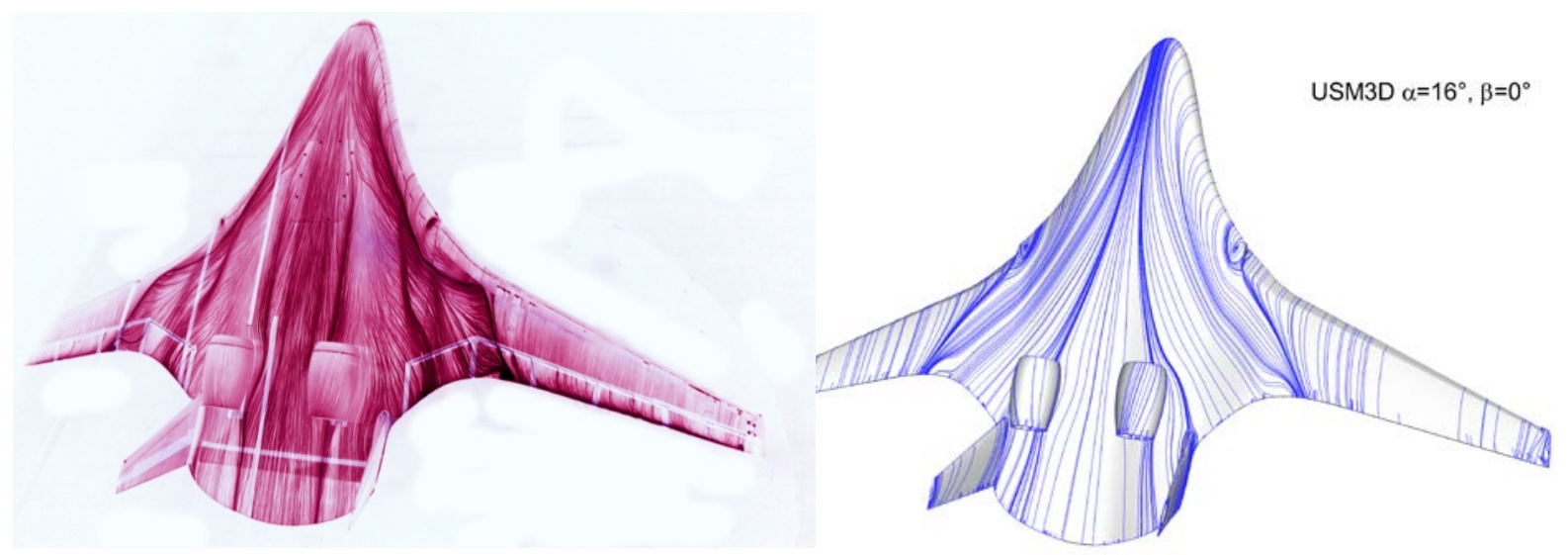

Figure 19. Surface oil flow and USM3D streakline comparison.

14

American Institute of Aeronautics and Astronautics 


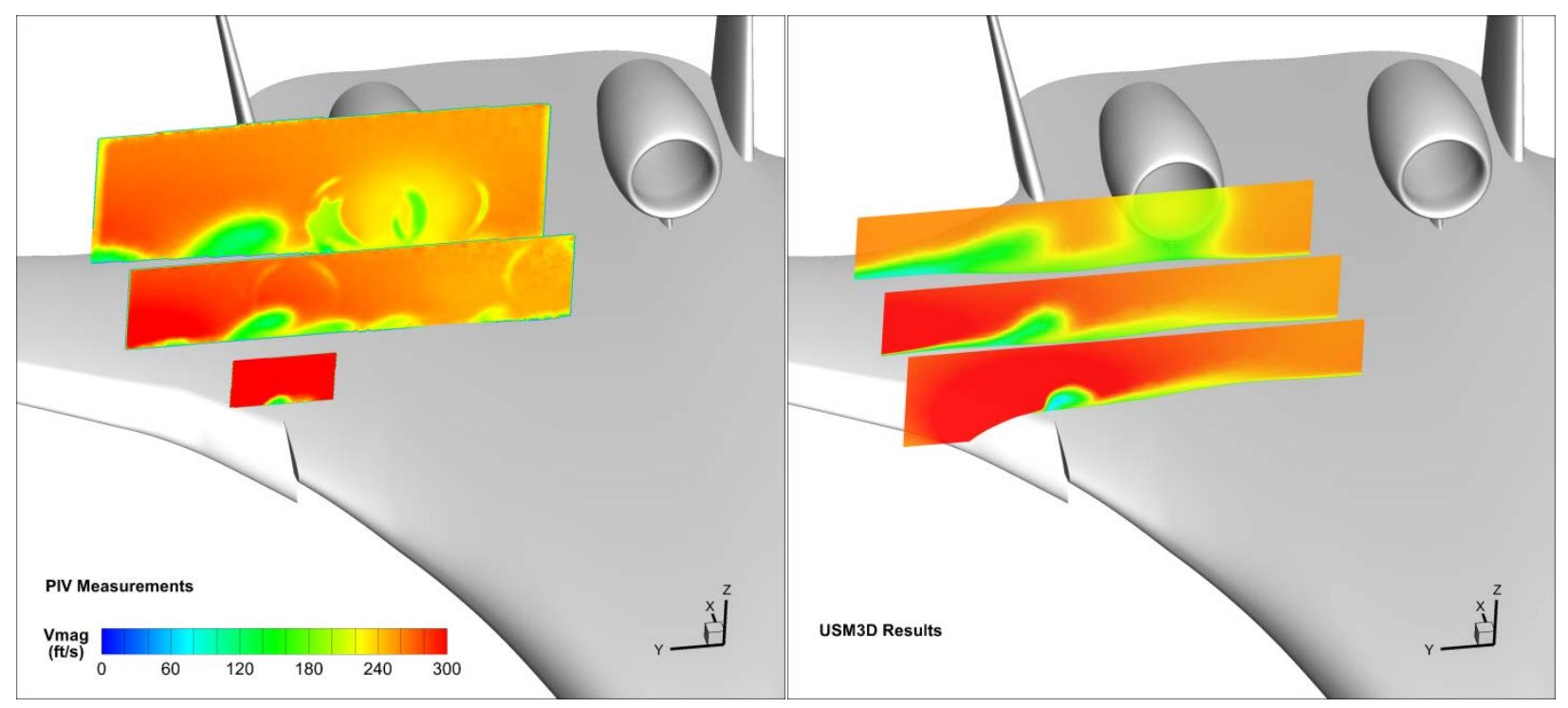

Figure 20. Velocity contour comparisons of PIV measurements and USM3D predictions (

CFD predicts a velocity that is $20 \%$ to $25 \%$ less than the PIV. The PIV results in the middle and aft planes provide examples of the effect of surface reflections of the laser light sheet on the final data. The circular pattern associated with the rim of the nacelle inlet is clearly visible. The green areas in the center of the lower velocity region and between the vortex and the nacelle are the result of laser light illuminating the inside of the nacelle and the outer surface. Although the model was painted black, the light intensity level in these areas made it extremely difficult to distinguish the particle signal from the background.

\section{Concluding Remarks}

Several experimental and computational investigations of a Hybrid Wing Body configuration have been conducted which comprise an extensive dataset on this non-proprietary configuration. This experimental dataset could be useful for future CFD code development and validation. Comparisons with a limited set of USM3D code predictions have highlighted regions where further investigation is warranted. Measurements comparisons between open and closed tunnel data have also highlighted the need for better tunnel corrections for wall and model support effects.

One of the concerns about this HWB configuration is nacelle inlet flow distortion, particularly with the drooped leading edge at moderate sideslip angles. None of the investigations showed a vortex propagating through the nacelle but the close proximity was enough to cause concern considering these were flow-thru nacelles without any engine induced mass flow. Impingement of the drooped leading edge inboard vortex on the vertical fin is another configuration issue highlighted from the tests.

\section{Acknowledgments}

The authors would like to acknowledge the staff of the 14- by 22-Foot Subsonic Tunnel for all their support in preparing and conducting the wind tunnel tests. In particular, Les Yeh is recognized for his leadership as test engineer. A special thanks to the PIV team of Scott Bartram, Dr. Chung-Sheng Yao, Jerome Harris and Derry Mace. Special acknowledgement is also warranted for the efforts of Brian Kramer and Michael Kerho of Rolling Hills Research Corporation for conducting and analyzing the water tunnel test. The NASA Environmentally Responsible Aviation project is gratefully acknowledged for the sponsorship of the wind tunnel tests and CFD analysis.

\section{References}

${ }^{1}$ Dowling, A. and Greitzer, E., “The Silent Aircraft Initiative - Overview,” AIAA-2007-0452, January 2007.

${ }^{2}$ Collier, F., Thomas, R., Burley, C., Nickol, C., Lee, M., and Tong, M., "Real Solutions For Environmental Challenges Facing Aviation,” ICAS-2010-1.6.1. 
${ }^{3}$ Schutte, J., Jimenez, H., and Mavris, D., "Technology Assessment of NASA Environmentally Responsible Aviation Advanced Vehicle Concepts,” AIAA-2011-6, January 2011.

${ }^{4}$ Nickol, C. and McCullers, A., "Hybrid Wing Body Configuration Systems Studies,” AIAA-2009-931.

${ }^{5}$ Kimmel, W., "Systems Analysis Approach for the NASA Environmentally Responsible Aviation Project," AIAA-2011-3528.

${ }^{6}$ Thomas, R., Burley, C., and Olson, E., "Hybrid Wing Body Aircraft System Noise Assessment With Propulsion Airframe Aeroacoustic Experiments,” AIAA 2010-3913.

${ }^{7}$ Hill, G., Brown, S., Geiselhart, K., and Burg, C., "Integration of Propulsion Airframe Aeroacoustic Technologies and Design Concepts for a Quiet Blended Wing Body Transport,” AIAA-2004-6306.

${ }^{8}$ Czech, M., Thomas, R., and Elkoby, R., "Propulsion Airframe Aeroacoustic Integration Effects of a Hybrid Wing Body Aircraft Configuration,” AIAA-2010-3912.

${ }^{9}$ Gatlin, G., Vicroy, D., and Carter, M., "Experimental Investigation of the Low-Speed Aerodynamic Characteristics of a 5.8-Percent Scale Hybrid Wing Body Configuration,” $30^{\text {th }}$ AIAA Applied Aerodynamics Conference, AIAA-2012-2669.

${ }^{10}$ Brooks, Thomas F., Hutcheson, Florence V., Burley, Casey L., and Plassman, Gerald E. “Airframe Noise Measurements for a Hybrid Wing Boyd Configuration in the NASA Langley 14 by 22 Foot Tunnel," 20th AIAA/CEAS Aeroacoustics Conference, Atlanta, GA, June 16-20, 2014 (submitted for publication).

${ }^{11}$ Brooks, Thomas F., et al., "Overview of the Hybrid Wing Body Aeroacoustics Test in NASA Langley 14 by 22 Foot Subsonic Tunnel,” 20th AIAA/CEAS Aeroacoustics Conference, Atlanta, GA, June 16-20, 2014 (submitted for publication).

${ }^{12}$ Burley, Casey L., et al., "Noise Scaling and Community Noise Metrics for the Hybrid Wing Body Aircraft," $20^{\text {th }}$ AIAA/CEAS Aeroacoustics Conference, Atlanta, GA, June 16-20, 2014 (submitted for publication).

${ }^{13}$ Kramer, Brian, and Kerho, Michael, “Aerodynamic Modeling in Unsteady Flight Regimes,” SBIR Phase III Final Report, Contract Number NNL12AA36C with NASA Langley Research Center, December 2, 2013.

${ }^{14}$ Murphy, Patrick C., Vicroy, Dan D., Kramer, Brian and Kerho, Michael., "Hybrid Wing Body Model Identification Using Forced-Oscillation Water Tunnel Data,” AIAA Atmospheric Flight Mechanics Conference, Atlanta, GA, June 16-20, 2014 (submitted for publication).

${ }^{15}$ Gentry, G. L., Jr.; Quinto, P. F.; Gatlin, G. M.; and Applin, Z. T.: The Langley 14- by 22-Foot Subsonic Tunnel: Description, flow Characteristics, and Guide for Users. NASA TP-3008, sept. 1990.

${ }^{16}$ Iyer, V. and Everhart, J., "Application of Pressure-Based Wall Correction Methods to Two NASA Langley Wind Tunnels,” AIAA-2001-2472, June 2001.

${ }^{17}$ Braslow, Albert L. and Knox, Eugene C.: "Simplified Method for Determination of Critical Height of Distributed Roughness Particles for Boundary-Layer Transition at Mach Numbers from 0 to 5.” NACA TN 4363, 1958.

${ }^{18}$ Frink, N. T.; Pirzadeh, S.Z.; Parikh, P.C.; Pandya, M.J.; and Bhat, M.K, "The NASA Tetrahedral Unstructured Software System”, The Aeronautical Journal, Vol. 104, No. 1040, October 2000, pp. 491-499.

${ }^{19}$ Lohner R and Parikh P., “Three-Dimensional Grid Generation by the Advancing Front Method.” International Journal for Numerical Methods in Fluids, Vol. 8, Issue 10, pp 1135-1149, Oct. 1988.

${ }^{20}$ Pirzadeh S., “Three-Dimensional Unstructured Viscous Grids by the Advancing Layers Method.” AIAA Journal, Vol. 34, No. 1, January 1996, pp. 43-49.

${ }^{21}$ Frink, N. T., “Three-Dimensional Upwind Scheme for Solving the Euler Equations on Unstructured Tetrahedral Grids”, Ph. D. Dissertation, Virginia Polytechnic Institute and State University, September 1991.

${ }^{22}$ Roe, P., "Characteristic Based Schemes for the Euler Equations.” Annual Review of Fluid Mechanics, Vol. 18, 1986, pp. 337-365.

${ }^{23}$ Spalart, P.; and Allmaras, S.A., “One-Equation Turbulence Model for Aerodynamic Flows.” AIAA 92-0439, January 1992.

${ }^{24}$ Menter, F.R., “Improved Two-Equation k-omega Turbulence Models for Aerodynamic Flows.” NASA TM-103975, October 1992

${ }^{25}$ Pandya, M. J.; Abdol-Hamid, K. S.; and Frink, N. T.: “Enhancement of USM3D Unstructured Flow Solver for High-speed High-Temperature Shear Flows”, AIAA 2009-1329, January 2009. 